\title{
Effect of Psyllium Fiber Supplementation on C-Reactive Protein: The Trial to Reduce Inflammatory Markers (TRIM)
}

\author{
Dana E. King, $M D^{1}$ \\ Arch G. Mainous III, PbD $D^{1,2}$ \\ Brent M. Egan, $M D^{3}$ \\ Robert F. Woolson, $\mathrm{PbD}^{2}$ \\ Mark E. Geesey, MS ${ }^{1}$ \\ 'Department of Family Medicine, Medical \\ University of South Carolina, Charleston \\ ${ }^{2}$ Department of Biostatistics, Bioinformatics, \\ and Epidemiology, Medical University of \\ South Carolina, Charleston \\ ${ }^{3}$ Department of Medicine, Medical Univer- \\ sity of South Carolina, Charleston
}

\begin{abstract}
PURPOSE Recent evidence supports a significant association between the intake of dietary fiber and levels of inflammatory markers. The objective of this study was to determine whether daily fiber supplementation would reduce levels of inflammatory markers.
\end{abstract}

METHODS This study was a prospective randomized controlled trial at a single university medical center. Participants were overweight or obese adults with no history of heart disease. The intervention was psyllium supplementation at either 7 or $14 \mathrm{~g} / \mathrm{d}$ for 3 months compared with no supplements in a control group. The main outcome measure was change in level of high-sensitivity C-reactive protein (hsCRP) concentration; secondary outcomes included changes in interleukin-6 (IL6) levels, fibrinogen levels, and white blood cell (WBC) count. Protocol completers attended at least 2 visits and took more than $75 \%$ of the prescribed fiber dose.

RESULTS In this intent-to-treat analysis $(n=158)$, there were no significant differences between either of the 2 treatment groups and the control group in the amount of change in CRP, fibrinogen, or IL- 6 levels or in WBC count $(P>.05)$. In the analysis of protocol completers $(n=132)$, there also were no significant differences between the groups except for a small decrease in fibrinogen level in the high-fiber group $(-6 \mathrm{mg} / \mathrm{dL}[-0.18 \mu \mathrm{mol} / \mathrm{L}]$ compared with $13 \mathrm{mg} / \mathrm{dL}[0.38$ $\mu \mathrm{mol} / \mathrm{L}]$ in the control group, $P<.05)$.

CONCLUSION Psyllium fiber supplementation did not significantly reduce CRP levels in overweight or obese individuals in this trial, and changes in other markers were not consistent. Further research is needed to determine whether other fibers or nutrients can reduce inflammatory markers.

Ann Fam Med 2008;6:100-106. DOI: 10.1370/afm.819.

\section{INTRODUCTION}

$I$ nflammation and dietary factors play important roles in cardiovascular risk. ${ }^{1-6}$ Diets high in fiber have been particularly associated with lower cardiovascular risk. ${ }^{5,6}$ Epidemiologic data also have shown an association between elevation of C-reactive protein (CRP) levels and cardiovascular risk in people with and without a history of heart disease. ${ }^{1,7}$ Elevated CRP levels are a common feature of obesity and also have been linked to insulin resistance, diabetes, the metabolic syndrome, hypertension, and other risk factors for cardiovascular diseases. ${ }^{8-14}$ A recent update of the American Heart Association dietary guidelines emphasizes a high-fiber diet and consumption of 25 to $30 \mathrm{~g}$ of fiber per day. ${ }^{15}$

Recent evidence supports a significant association between the intake of dietary fiber and CRP. ${ }^{16}$ A previous study examined the relation of dietary fiber to levels of CRP among adults with diabetes, hypertension, or obesity in the National Health and Nutrition Examination Survey (NHANES) and found an average intake of $13.5 \mathrm{~g}$ of dietary fiber per day. ${ }^{14}$ In that 
study, after controlling for demographic factors, body mass index (BMI), cardiovascular risk factors, and total caloric intake, participants in the lowest quartile of fiber consumption with 2 or more risk conditions had an increased risk of elevated CRP (odds ratio [OR] 2.25; 95\% confidence interval [CI], 1.38-3.67) compared with those in the highest quartile of fiber consumption. ${ }^{14}$ Another recent study ${ }^{17}$ that examined 524 subjects with multiple measurements of CRP and dietary factors also observed an inverse association between intake of total dietary fiber and CRP levels in both cross-sectional and longitudinal analyses $(P<.05)$. The likelihood of elevated CRP levels was 63\% lower (OR, 0.37; 95\% CI, $0.16-0.87)$ in participants in the highest quartile of total fiber intake than in participants in the lowest quartile. ${ }^{17}$ These studies are consistent but rely on cross-sectional or cohort analyses. A recent randomized trial of dietary fiber showed no significant relationship between the dietary fiber intervention and CRP concentrations except in a subgroup of lean normotensive individuals. ${ }^{18}$ Consequently, the impact of dietary fiber or fiber supplementation on inflammation is unclear, particularly as an intervention among overweight or obese individuals who have higher cardiovascular risk. ${ }^{19,20}$

A prospective trial of fiber supplementation to investigate the effects suspected from epidemiologic studies was warranted according to the emerging evidence. ${ }^{13,16,18}$ In the current study, we set out to examine the impact of 3 months of psyllium fiber supplementation on CRP and other inflammatory markers in 162 overweight or obese adults.

\section{METHODS}

This study was a randomized controlled trial of fiber supplementation at 2 doses $(14 \mathrm{~g} / \mathrm{d}$ and $7 \mathrm{~g} / \mathrm{d})$ compared with no supplement in 162 adult volunteers aged 40 to 65 years. The study was approved by the Institutional Review Board at the Medical University of South Carolina (MUSC), Charleston, and registered at clinicaltrials.gov (NCT00085800). The study was performed at the General Clinical Research Center (GCRC) at MUSC and approved by the GCRC Advisory Committee. An external data safety-monitoring board reviewed progress regularly throughout the trial. The trial was designed to have $80 \%$ power to detect standardized mean differences in CRP concentrations between the high-fiber supplementation and control groups of approximately $0.6 \mathrm{mg} / \mathrm{L}$ using 43 subjects per group.

Participants were eligible if they were aged 40 to 64 years, gave informed consent, had a BMI of greater than $25 \mathrm{~kg} / \mathrm{m}^{2}$, and had stable weight for the last 3 months (no change more than $\pm 5 \%$ ). In addition, participants needed to have a CRP concentration of greater than
$3.0 \mathrm{mg} / \mathrm{L}$ for women and greater than $2.0 \mathrm{mg} / \mathrm{L}$ for men to account for the differences in CRP levels by sex (median $\mathrm{CRP}=3.3 \mathrm{mg} / \mathrm{L}$ in women vs $1.8 \mathrm{mg} / \mathrm{L}$ in men; $P<.001) .{ }^{21,22}$ The study focused on individuals with a BMI of greater than $25 \mathrm{~kg} / \mathrm{m}^{2}$ because of the impact of BMI on CRP levels and the great proportion of individuals who are overweight or obese and who have elevated CRP levels. ${ }^{8}$ Patients were excluded for pregnancy, regular use of a fiber supplement of more than $4 \mathrm{~g} / \mathrm{d}$, a history of known cardiovascular disease (including myocardial infarction, stroke, congestive heart failure, or history of revascularization procedure [bypass, angioplasty, or stent placement]), uncontrolled hypertension (>170/95 $\mathrm{mm} \mathrm{Hg}$ ), electrocardiographic evidence of ischemia or infarction, recent (within 90 days) or planned participation in a formal weight loss program, and a history of inflammatory disease, including collagen vascular disease, inflammatory arthritis, recent serious infection, or other inflammatory condition. Patients were permitted to continue taking current medications, including aspirin, coenzyme A reductase inhibitors, or thiazolidinediones, but were allowed no new medication within 90 days and no change in dosage for the last 30 days.

After a screening visit at the GCRC to determine eligibility, eligible patients were randomized using an online randomization program kept confidential from the primary investigators. Participants were assigned to either the low-dose psyllium group $(7 \mathrm{~g} / \mathrm{d})$, the highdose psyllium group (14 g/d), or control (no psyllium) (Figure 1). Study investigators (except the research coordinator) were blinded to assignments and did not see study data until the trial was completed; the participants were not blinded to assignment group. After a baseline laboratory evaluation, history, and physical examination, the patients were scheduled to return to the GCRC in 1 month, and again in 3 months for follow-up. Measurements of CRP (highsensitivity [hsCRP]) concentration, white blood cell (WBC) count, fibrinogen level, and interleukin-6 (IL-6) concentration were obtained at baseline, because previous research found them to be inflammatory markers and associated to some degree with cardiovascular risk. ${ }^{1,4,23,24}$ CRP, WBC, IL-6, and fibrinogen values were also obtained at the final 3-month follow-up visit.

Participants were given fiber supplements in powder form in packets containing $3.5 \mathrm{~g}$ of psyllium fiber each. The low-fiber supplementation group took 2 packets each day between meals mixed in water; the high-fiber supplementation group took 4 packets each day spread throughout the day between meals. Participants in the intervention were instructed to take 1 packet daily in no-pulp orange juice to match control participants, who were told to drink 18 -ounce glass of no-pulp orange juice daily. Participants on fiber supple- 
Figure 1. Trial profile: disposition of screened, randomized, and analyzed patients.

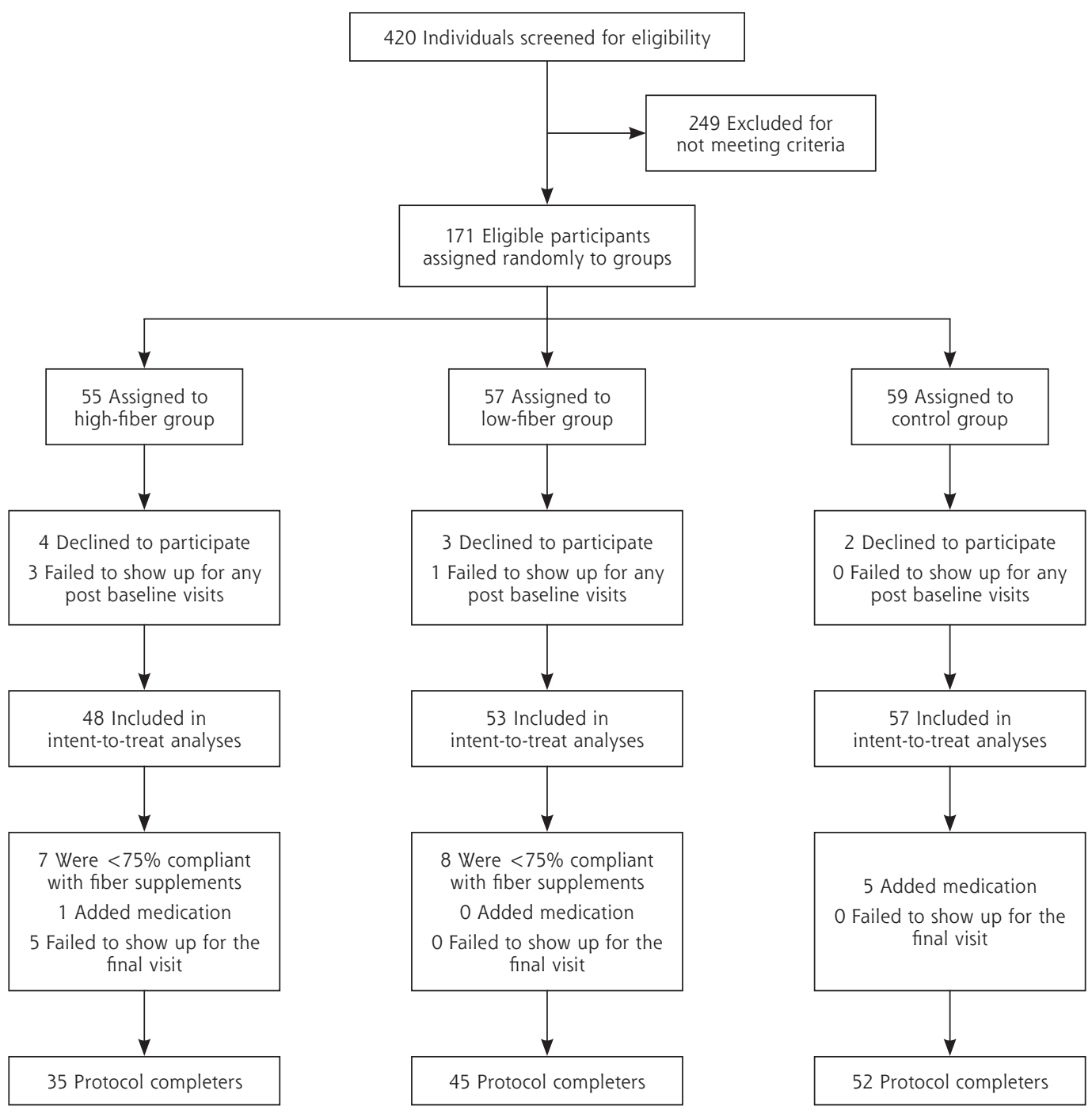

mentation took the remaining doses of psyllium mixed only with water. Compliance was assessed at each visit using fiber packet counts.

To determine eligibility for the study, blood samples for CRP measurement were drawn using standard phlebotomy techniques and sent for analysis in the CLIA-certified MUSC laboratory. Participants' serum CRP concentration was determined by a high-sensitivity method using the IMMAGE Immunochemistry System (Beckman Coulter, Brea, California). The IMMAGE CRP reagent is based on the highly sensitive near infrared particle immunoassay rate method. The analytical range for the IMMAGE system was 0.2 $\mathrm{mg} / \mathrm{L}$ to $60 \mathrm{mg} / \mathrm{L}$. For the primary outcome analyses for CRP levels, frozen sera from participants were sent as paired samples (baseline and 3 months) to an outside reference laboratory (Emory General Clinical Research
Core Laboratory, Atlanta, Georgia), and samples were analyzed using a commercial ELISA kit from ALPCO Diagnostics (Salem, New Hampshire). For hsCRP determinations, frozen plasma samples were thawed at room temperature and centrifuged at $16,000 \mathrm{~g}$ for 10 minutes to remove any precipitate. Samples were diluted 1:1000, and hsCRP concentrations were measured, in duplicate, using the ELISA kit from ALPCO Diagnostics (assay sensitivity, $0.124 \mathrm{ng} / \mathrm{mL}$; assay range, $1.9-150 \mathrm{ng} / \mathrm{mL}$ ).

For IL- 6 measurements, blood was collected using standard phlebotomy techniques and frozen to $-20^{\circ} \mathrm{C}_{\text {; }}$ paired samples were sent to Associated Regional and University Pathologists, Inc (ARUP) laboratories in Salt Lake City, Utah, and analyzed with an IMMULITE analyzer (Diagnostics Products Corporation, Los Angeles, Calif) using chemiluminescence technique 
and a sequential immunometric assay. ${ }^{25}$ The analytic range of the system was 5.0 to $1,000 \mathrm{pg} / \mathrm{mL}$. Fibrinogen was determined in MUSC laboratories using the Clauss clotting method (STAR Diagnostics, Dallas, Texas). ${ }^{26} \mathrm{WBC}$ count was determined based on the optical scatter and fluorescence technique (Cell-Dyne 4000, Abbott, Abbott Park, Illinois). ${ }^{27}$

The primary analysis was intent-to-treat and focused on changes in the CRP level in the high-fiber group compared with the changes in the control group during the 3 -month study. The primary outcome of the study was change in CRP level from baseline to the final month 3 visit. The primary comparison was between the mean changes from baseline to 3 months in the high-fiber supplementation group compared with the control group at month 3 using the 2-sample $t$ test. The intent-to-treat analysis included all participants for whom there were postbaseline values. Analysis was done using last value carried forward to account for missing values at the final visit.

In secondary analyses, the mean change in CRP levels from baseline to 3 months also was compared between the low-fiber supplementation group and control group. Because CRP levels are not normally distributed, differences in the natural log transformed CRP levels were also examined. Fibrinogen levels and WBC count also were compared using the same comparisons as for CRP levels. The level of detection for IL- 6 was $2.0 \mathrm{pg} / \mathrm{mL}$, and many of the participants had levels below the detection limit. As a result, for IL- 6 groups were compared using the percentage of each group above and below the baseline median IL- 6 concentration ( median $=2.55$ $\mathrm{pg} / \mathrm{mL}$ ). An analysis of protocol completers done separately from the main intent-to-treat analysis included participants who attended the final visit, consumed at least $75 \%$ of the prescribed supplement, and did not add any medications known to affect inflammation (statins, thiazolidinediones, and corticosteroids). Throughout the statistical analyses 2 -sample $t$ tests (or $\chi^{2}$ for categorical variates) comparing the high-fiber supplementation and control groups were the primary comparisons specified in the protocol design. There was no prespecified plan to adjust the type
I error rate for this primary trial comparison of these 2 treatment arms. Statistical significance was specified in advance at an $\alpha$ of .05.

We conducted linear regression modeling of the effect of fiber supplement group on the changes in inflammatory markers. These regressions also incorporated BMI $\left(\mathrm{kg} / \mathrm{m}^{2}\right)$ as a control factor. CRP was treated linearly and was log-transformed in separate regressions to account for skewness. In addition, we analyzed the response to fiber supplementation according to baseline fiber intake. We also stratified the participants into those who were or were not taking stable doses of medications that might interfere with CRP levels (aspirin, statins, and glitazones) and analyzed change in CRP levels and other markers comparing the 2 groups.

\section{RESULTS}

The trial profile and selection of participants are outlined in Figure 1. Among the 420 adults screened for elevated CRP levels, 171 met entry criteria. Nine participants dropped out after the screening and before the baseline visit, leaving 162 who participated in the complete baseline evaluation. These 162 are referred to as "the randomized patient population" in Table 1.

\section{Table 1. Initial Demographic Characteristics of the Randomized Patient Population $(n=162)$ by Fiber Group.}

\begin{tabular}{|c|c|c|c|c|}
\hline Characteristic & High Fiber & Low Fiber & Control & $P$ Value \\
\hline No. & 51 & 54 & 57 & \\
\hline Sex, \% & & & & $.68^{\mathrm{a}}$ \\
\hline Male & 25.5 & 31.5 & 24.6 & \\
\hline Female & 74.5 & 68.5 & 75.4 & \\
\hline Race, \% & & & & $.43^{\mathrm{a}}$ \\
\hline Black & 35.3 & 50.0 & 49.1 & \\
\hline White & 62.8 & 48.2 & 50.9 & \\
\hline Other & 2.0 & 1.8 & 0 & \\
\hline Smoker, \% & & & & $.88^{\mathrm{a}}$ \\
\hline Never & 60.8 & 63.0 & 64.9 & \\
\hline Former & 19.6 & 22.2 & 22.8 & \\
\hline Current & 19.6 & 14.8 & 12.3 & \\
\hline Diabetic, \% & 15.7 & 18.5 & 15.8 & $.91^{\mathrm{a}}$ \\
\hline Hypertensive, \% & 31.4 & 51.9 & 36.8 & $.08^{\mathrm{a}}$ \\
\hline Taking statin medication, \% & 13.7 & 18.5 & 15.8 & $.80^{\mathrm{a}}$ \\
\hline Age, years, mean (SD) & $51.4(6.4)$ & $50.6(6.1)$ & $49.4(6.1)$ & $.22^{\mathrm{b}}$ \\
\hline $\begin{array}{l}\text { Body mass index, } \mathrm{kg} / \mathrm{m}^{2} \\
\text { mean (SD) }\end{array}$ & $33.8(5.9)$ & $32.6(5.6)$ & $33.7(6.6)$ & $.55^{\mathrm{b}}$ \\
\hline Dietary fiber, g/d, mean (SD) & $14.5(3.9)$ & $13.5(3.4)$ & $14.1(4.4)$ & $.42^{\mathrm{b}}$ \\
\hline Fibrinogen, mg/dL, mean (SD) & $387.9(75.7)$ & $389.8(79.5)$ & $380.8(61.9)$ & $.80^{\mathrm{b}}$ \\
\hline $\begin{array}{l}\text { White blood cell count, } \\
1,000 / \mu \mathrm{L} \text {, mean (SD) }\end{array}$ & $6.38(2.1)$ & $6.16(1.9)$ & $6.17(1.9)$ & $.81^{\mathrm{b}}$ \\
\hline $\begin{array}{l}\text { C-reactive protein level, } \\
\mathrm{mg} / \mathrm{L} \text {, mean }(\mathrm{SD})\end{array}$ & $7.61(5.8)$ & $7.62(6.7)$ & $7.79(7.5)$ & $.99^{\mathrm{b}}$ \\
\hline
\end{tabular}


Within this group, 4 failed to attend any further visits, leaving 158 participants in the intent-to treat group. There were 5 participants (all in the high-fiber supplementation group) who attended the 1 -month visit, but not the 3-month visit; thus, data from the 1-month visit was carried forward and used as the final data for these participants in the intent-to-treat analyses. (Analyses excluding these 5 patients also produced the same findings but are not reported for sake of brevity.) Participants who did not show for the 3-month follow-up visit (5), were less than $75 \%$ compliant with the fiber supplementation regimen (15), or added medications that could potentially decrease inflammatory markers (6) were excluded from the analysis of protocol completers (132 participants). Among those who added new medications, 4 added atorvastatin, 1 added rosiglitazone, and 1 added prednisone.

The 3 study groups were balanced for demographic and clinical characteristics including age, sex, race, smoking status, and BMI (Table 1). There were also no significant differences in baseline characteristics (fibrinogen level, WBC count, or CRP concentration between either of the 2 treatment groups receiving fiber supplements and the control group $(P>.05)$. Compliance rates were not different between the low-fiber and high-fiber supplementation groups $(P=.94)$. There were no significant adverse events attributed to treatment in any of the intervention groups.

In the intent-to-treat analysis, there were no significant differences between either of the 2 treatment groups and the control group in the amount of change in CRP levels, fibrinogen levels, or WBC counts $(P>.05)$ (Table 2$)$. In the secondary analysis of study protocol completers (attended visit $3, \geq 75 \%$ compliant, no additions to medication), there also were no significant differences between either of the treatment groups and the control group for changes in any of the inflammatory marker outcomes except for fibrinogen (Table 3). The by Fiber Group distribution of IL-6 levels was also not significantly different between the treatment groups, except that a lower percentage of participants in the low-fiber group had IL- 6 levels above the median than either of the other 2 groups $\left(\chi^{2} ; P=.043\right)$ (Table 4$)$. The high-fiber supplementation group did have a significant decrease in mean fibrinogen levels $(-6 \mathrm{mg} / \mathrm{L}[-0.18 \mu \mathrm{mol} / \mathrm{L}]$ compared with $13 \mathrm{mg} / \mathrm{L}[0.38 \mu \mathrm{mol} / \mathrm{L}]$ in the control group; $P<.05)$.

In adjusted linear regression analyses, after controlling for BMI, the high-fiber supplementation group showed a significant decrease in fibrinogen levels compared with the control group $(P=.03)$. No other
Table 2. Changes in Inflammatory Markers (Intent-to-Treat) From Baseline to 3 Months Among Randomized Participants, by Fiber Group

\begin{tabular}{lccl}
\hline Inflammatory Marker & $\begin{array}{c}\text { High Fiber } \\
(\mathbf{n}=\mathbf{4 8})\end{array}$ & $\begin{array}{c}\text { Low Fiber } \\
\mathbf{( n = 5 3 )}\end{array}$ & $\begin{array}{c}\text { Control } \\
\mathbf{( n = 5 7 )}\end{array}$ \\
\hline $\begin{array}{l}\text { C-reactive protein, mg/L, } \\
\text { mean (SD) }\end{array}$ & $0.98(4.57)$ & $-0.96(4.45)$ & $0.05(7.87)$ \\
$\begin{array}{l}\text { Fibrinogen, mg/dL, } \\
\text { mean (SD) }\end{array}$ & $-2.44(32.69)$ & $-2.29(35.34)$ & $10.32(48.92)$ \\
$\begin{array}{l}\text { White blood cell count, } \\
1,000 / \mu \mathrm{L}, \text { mean (SD) }\end{array}$ & $0.01(1.02)$ & $0.08(0.87)$ & $-0.09(1.05)$ \\
\hline
\end{tabular}

Table 3. Changes in Inflammatory Markers Between Baseline and 3 Months Among Patients Who Were at Least 75\% Compliant With Fiber Supplementation and Had No Additions to Medication,

\begin{tabular}{|c|c|c|c|}
\hline Inflammatory Marker & $\begin{array}{l}\text { High Fiber } \\
(\mathrm{n}=35)\end{array}$ & $\begin{array}{l}\text { Low Fiber } \\
(\mathrm{n}=45)\end{array}$ & $\begin{array}{l}\text { Control } \\
(n=52)\end{array}$ \\
\hline C-reactive protein, mg/L, mean (SD) & $0.50(4.67)$ & $-1.12(4.78)$ & $0.36(7.94)$ \\
\hline Fibrinogen, mg/dL, mean (SD) & $-6.30(34.52)^{\mathrm{a}}$ & $4.20(35.42)$ & $13.02(48.62)$ \\
\hline $\begin{array}{l}\text { White blood cell count, } 1,000 / \mu \mathrm{L} \text {, } \\
\text { mean (SD) }\end{array}$ & $0.08(0.89)$ & $0.12(0.92)$ & $-0.01(1.05)$ \\
\hline
\end{tabular}

Table 4. Distribution of Interleukin-6 Levels by Fiber Group in the Initial Randomized Patient Population, and After 3 Months, in the Intent-to-Treat Population and Among Protocol Completers

\begin{tabular}{ccccc}
\hline Interleukin-6 Level & High Fiber & Low Fiber & Control & P Value $^{\text {a }}$ \\
\hline Initial population, No. & 42 & 51 & 54 & .043 \\
$\leq 2.5 \mathrm{pg} / \mathrm{mL}, \%$ & 45.2 & 62.8 & 38.9 & \\
$>2.5 \mathrm{pg} / \mathrm{mL}, \%$ & 54.8 & 37.3 & 61.1 & \\
Intent-to-treat, No. & 41 & 51 & 56 & .217 \\
$\leq 2.5 \mathrm{pg} / \mathrm{mL}, \%$ & 48.8 & 31.4 & 42.9 & \\
$>2.5 \mathrm{pg} / \mathrm{mL}, \%$ & 51.2 & 68.6 & 57.1 & \\
Protocol completers, No. & 34 & 44 & 51 & .178 \\
$\leq 2.5 \mathrm{pg} / \mathrm{mL}, \%$ & 50.0 & 29.6 & 41.2 & \\
$>2.5 \mathrm{pg} / \mathrm{mL}, \%$ & 50.0 & 70.5 & 58.8 & \\
\hline a Determined by $x^{2}$ analysis. & & & \\
\hline
\end{tabular}


inflammatory markers showed any statistically significant differences between intervention and control groups after 3 months. In further regression analyses taking into account baseline fiber intake, there were no differences in CRP levels from baseline to 3 months between treatment groups. Further, no differences were seen between groups when groups were stratified according to whether they were taking stable doses of medications that might interfere with CRP levels.

\section{DISCUSSION}

In this randomized trial of psyllium fiber supplementation among overweight and obese adults, there were no significant reductions in CRP levels from baseline to 3 months in the high-fiber group compared with controls in the intent-to-treat analysis. In secondary analyses of IL- 6 concentrations, WBC counts, and fibrinogen levels, there were no differences between treatment groups. In further analyses of protocol completers, a small reduction in fibrinogen level was found from baseline to 3 months in the high-fiber supplementation group compared with the control group, which in the context of other study results is likely not clinically significant. The trial was conducted at a single study center but had a racially diverse population with substantial representation of both whites and blacks (approximately 50\% each). Analyses stratified according to BMI, baseline fiber intake, or use of other medications also yielded no statistically significant differences in inflammatory markers between fiber supplementation and control groups at 3 months.

These trial results contrast with previous crosssectional and cohort analyses that suggested an association of dietary fiber intake with CRP concentration. ${ }^{16,17}$ The results are consistent with the findings of a recent clinical trial that found little change in CRP levels among obese hypertensive individuals taking a psyllium fiber supplement, but that previous trial was small $(\mathrm{N}=35)$ and supplementation was for only 3 weeks. ${ }^{18}$ The current results add confirmation to the notion that fiber supplementation with psyllium does not significantly reduce CRP levels in overweight or obese individuals.

Although disappointing, the current findings may not be unprecedented when examining the evidence from other dietary supplements trials that followed epidemiological evidence of dietary intake and a health outcome. For example, oxidative stress is associated with cardiovascular disease, and epidemiological evidence suggested that individuals with diets high in fruits and vegetables or antioxidants had lower rates of cardiovascular disease. When randomized clinical trials were conducted to examine the impact of anti- oxidants. such as vitamin $\mathrm{E}_{,}^{28,29}$ on cardiovascular disease, however, the interventions were not successful. ${ }^{30}$ These results do not suggest that the epidemiological evidence is faulty or that the underlying mechanism regarding oxidative stress and cardiovascular disease needed to be modified; they suggest that perhaps isolating vitamin E from one's diet into a supplement may not represent the behavior of a diet high in fruits and vegetables. In a similar way, the current findings do not negate the importance of a diet naturally high in fiber, ${ }^{31,32}$ but they do suggest that taking a psyllium supplement may not be an effective way to reduce inflammation and presumably risk of cardiovascular disease.

There are several limitations to this study that may suggest alternative explanations. First, this study used only one type of fiber (psyllium) as the intervention supplement, and it was not blinded for the participants. Further, although both a high- and low-fiber dose was included in the study, it is possible that other types of fiber, such as pectin or oats, could have yielded different results. Psyllium seemed to be the ideal choice because of its tolerability and that psyllium supplements did result in some lowering of CRP levels among lean individuals. ${ }^{18}$ Second, the length of the study may have affected the impact of the fiber supplementation intervention. It is possible that fiber supplementation requires longer than the 3 months allocated in this study to have a substantial effect on inflammation. Third, patient characteristics other than BMI may have influenced the effect of the intervention across the groups. Even so, the randomization schedule and the lack of differences between the groups suggest that known and unknown characteristics were randomly distributed across the groups. Finally, although the study was designed to have $80 \%$ power to detect a 20\% change in CRP levels, the differences between groups did not meet this criterion, and the study may have been underpowered. There was, however, no trend or slope seen in the current study to hint at undetected changes, and the previous study of psyllium supplementation also found only modest changes $(10 \%)$ in obese persons ${ }^{18}$; thus the current negative study result is fairly well substantiated.

In conclusion, the current study did not find a significant impact of psyllium fiber supplementation on CRP levels or other inflammatory markers. This finding does not negate the epidemiologic evidence that dietary fiber is a factor in reducing inflammation ${ }^{16}$ or the risk of cardiovascular disease, ${ }^{33}$ but it does suggest that fiber supplementation with psyllium does not replicate the results seen with a diet naturally high in fiber. Further research with other types of fiber or with combinations of nutrients may be warranted. 


\section{To read or post commentaries in response to this article, see it} online at http://www.annfammed.org/cgi/content/full/6/2/100.

Key words: Inflammation; dietary supplements; dietary fiber; C-reactive protein; psyllium

Submitted May 7, 2007; submitted, revised, September 4, 2007; accepted October 8, 2007.

Funding support: This study was supported by grant RR 01070 from the General Clinical Research Center, grant R01 HL076271 from National Heart, Lung, and Blood Institute, and grant HL58794 from the National Institutes of Health, which approved the design and conduct plans for the study, but had no role in preparation, review or approval of the manuscript.

Acknowledgments: The authors would like to thank the members of the Data Safety Monitoring Board for their oversight of the study and helpful suggestions throughout the process: David Calhoun, MD, chair, Medical Director, University of Alabama at Birmingham, Vascular Biology \& Hypertension Program, Birmingham, Alabama; Peter M. Meyer, PhD, Associate Professor and Director, Section of Biostatistics, Department of Preventive Medicine, Rush University Medical Center, Chicago, Illinois; and Thomas (Tate) P. Erlinger, MD, MPH, UT Medical Branch-Austin Outreach, Austin, Texas. The authors would also like to thank Tina Ellis, MS, for her role as study coordinator throughout the duration of this study.

\section{References}

1. Ridker PM, Stampfer MJ, Rifai N. Novel risk factors for systemic atherosclerosis. JAMA. 2001;285(19):2481-2485.

2. Ridker PM, Rifai N, Rose L, Buring JE, Cook NR. Comparison of C-reactive protein and low-density lipoprotein cholesterol levels in the prediction of first cardiovascular events. $N$ Engl J Med. 2002;347(20):1557-1565.

3. Ridker PM. C-reactive protein, inflammation, and cardiovascular disease: clinical update. Tex Heart Inst J. 2005;32(3):384-386.

4. Pearson TA, Mensah GA, Alexander RW, et al. AHA/CDC Scientific Statement. Markers of Inflammation and Cardiovascular Disease. Circulation. 2003;107(3):499-511.

5. Stampfer MJ, Hu FB, Manson JE, Rimm EB, Willett WC. Primary prevention of coronary heart disease in women through diet and lifestyle. N Engl J Med. 2000;343(1):16-22.

6. Liu S, Burning J, Sesso H, Rimm E, Willett W, Manson J. A prospective study of dietary fiber intake and risk of cardiovascular disease among women. J Am Coll Cardiol. 2002;39(1):49-56.

7. Morrow DA, Ridker PM. Risk factor modification for cardiac disease: C-reactive protein, inflammation, and coronary risk. Med Clin North Am. 2000;84(1):149-161.

8. Ford ES. Body mass index, diabetes, and C-reactive protein among U.S. adults. Diabetes Care. 1999;22(12):1971-1977.

9. Ridker PM, Buring JE, Cook NR, Rifai N. C-reactive protein, the metabolic syndrome, and risk of incident cardiovascular events: an 8-year follow-up of 14,719 initially healthy American women. Circulation. 2003;107(3):391-397.

10. Taniguchi A, Nagasaka S, Fukushima M, et al. C-reactive protein and insulin resistance in non-obese Japanese type 2 diabetic patients. Metabolism. 2002;51(12):1578-1581.

11. Pradhan AD, Manson JE, Rifai N, Buring JE, Ridker PM. C-reactive protein, interleukin 6 , and risk of developing type 2 diabetes mellitus. JAMA. 2001;286(3):327-334.
12. Freeman DJ, Norrie J, Caslake MJ, et al. C-reactive protein is an independent predictor of risk for the development of diabetes in the West of Scotland Coronary Prevention Study. Diabetes. 2002;51(5):1596-1600.

13. King DE. Dietary fiber, inflammation, and cardiovascular disease. Mol Nutr Food Res. 2005;49(6):594-600.

14. King DE, Mainous AG III, Egan BM, Woolson RF, Geesey ME. Fiber and -reactive protein in diabetes, hypertension, and obesity. Diabetes Care. 2005;28(6):1487-1489.

15. American Heart Association Dietary Guidelines, Making Healthy Choices. http://www.americanheart.org/presenter. jhtml?identifier=537. Accessed February 21, 2007.

16. King DE, Egan BM, Geesey ME. Relation of dietary fat and fiber to elevation of C-reactive protein. Am J Cardiol. 2003;92(11):1335-1339. Erratum in : Am J Cardiol. 93(6):812..

17. Ma Y, Griffith JA, Chasan-Taber L, et al. Association between dietary fiber and serum C-reactive protein. Am J Clin Nutr. 2006;83(4):760-766.

18. King DE, Egan BM, Woolson RF, Mainous AG III, Al-Solaiman Y, Jesri A. Effect of a high-fiber diet vs. a fiber-supplemented diet on Creactive protein. Arch Intern Med. 2007;167(5):502-506.

19. Wilson PW, Kannel WB. Obesity, diabetes, and risk of cardiovascular disease in the elderly. Am J Geriatr Cardiol. 2002;11(2):119-125.

20. Berenson GS. Obesity-a critical issue in preventive cardiology: the Bogalusa Heart Study. Prev Cardiol. 20051;8(4):234-241.

21. Khera A, McGuire DK, Murphy SA, et al. Race and gender differences in C-reactive protein levels. J Am Coll Cardiol. 2005;46(3):464-469.

22. Albert MA, Ridker PM. C-reactive protein as a risk predictor: do race/ethnicity and gender make a difference? Circulation. 2006;114(5)e67-e74..

23. Kakafika AI, Liberopoulos EN, Mikhailidis DP. Fibrinogen: a predictor of vascular disease. Curr Pharm Des. 2007;13(16):1647-1659.

24. Kakafika AI, Liberopoulos EN, Mikhailidis DP. Fibrinogen: a predictor of vascular disease. Curr Pharm Des. 2007;13(16):1647-1659.

25. Lubrano V, Cocci F, Battaglia D, Papa A, Marraccini P, Zucchelli GC. Usefulness of high-sensitivity IL- 6 measurement for clinical characterization of patients with coronary artery disease. J Clin Lab Anal. 2005;19(3):110-114.

26. Palareti G, Maccaferri M. Specific assays of hemostasis proteins: fibrinogen. Ric Clin Lab. 1990;20(2):167-176.

27. Haim M, Boyko V, Goldbourt U, Battler A, Behar S. Predictive value of elevated white blood cell count in patients with preexisting coronary heart disease: the Bezafibrate Infarction Prevention Study. Arch Intern Med. 2004;164(4):433-439.

28. Vivekananthan DP, Penn MS, Sapp SK, Hsu A, Topol EJ. Use of antioxidant vitamins for the prevention of cardiovascular disease: metaanalysis of randomised trials. Lancet. 2003;361(9374):2017-2023.

29. Lee IM, Cook NR, Gaziano JM, et al. Vitamin E in the primary prevention of cardiovascular disease and cancer: the Women's Health Study: a randomized controlled trial. JAMA. 2005;294(1):56-65.

30. Woodside JV, McCall D, McGartland C, Young IS. Micronutrients: dietary intake v. supplement use. Proc Nutr Soc. 2005;64(4):543-553.

31. Esmaillzadeh A, Kimiagar M, Mehrabi Y, Azadbakht L, Hu FB, Willett WC. Fruit and vegetable intakes, C-reactive protein, and the metabolic syndrome. Am J Clin Nutr. 2006;84(6):1489-1497.

32. Hung $\mathrm{HC}$, Joshipura $\mathrm{KJ}$, Jiang $\mathrm{R}$, et al. Fruit and vegetable intake and risk of major chronic disease. J Natl Cancer Inst. 2004;96(21):1577-1584.

33. Flight I, Clifton P. Cereal grains and legumes in the prevention of coronary heart disease and stroke: a review of the literature. Eur J Clin Nutr. 2006;60(10):1145-1159. 